\title{
A Prospectively Studied Near-Death Experience with Corroborated Out-of-Body Perceptions and Unexplained Healing
}

Penny Sartori, R.G.N., Ph.D. Morriston Hospital, Swansea, South Wales Paul Badham, Ph.D. Alister Hardy Religious Experience Research Centre, University of Wales, Lampeter Peter Fenwick, M.B.B.Chir., D.P.M. Department of Mental Health, Southampton Institute of Psychiatry, Kings College, London

\begin{abstract}
There are reports of veridical out-of-body experiences (OBEs) and healing occurring during near-death experiences (NDEs). We report a case in which there was strong evidence for both healing and a veridical OBE. The patient's experience was thought to have occurred while he was unconscious in an intensive therapy unit (ITU). The patient's account of an OBE contained many veridical elements that were corroborated by the medical team attending his medical emergency. He had suffered from a claw hand and hemiplegic gait since birth. After the experience he was able to open his hand and his gait showed a marked improvement.
\end{abstract}

KEY WORDS: near-death experience; out-of-body experience; prospective study; healing.

Penny Sartori, R.G.N., Ph.D., is a nurse in the Intensive Therapy Unit at Morriston Hospital, Swansea, South Wales. Paul Badham, Ph.D., is Professor of Theology and Religious Studies and Director of the Alister Hardy Religious Experience Research Centre at the University of Wales, Lampeter. Peter Fenwick, M.B.B.Chir., D.P.M., F.R.C.Psych., is a neuropsychiatrist with the Department of Mental Health, Southampton, England, and the Institute of Psychiatry, Kings College, London. Reprint requests should be addressed to Dr. Sartori at the Intensive Therapy Unit, Morriston Hospital, Swansea, South Wales, UK, SA6 6NL; e-mail: drpennysartori@yahoo.co.uk. 
A number of studies have found that some patients who report neardeath experience (NDEs) during cardiac arrest experience out-of-body phenomena (Greyson, 2003; Lawrence, 1995, 1997; Sabom 1982, 1998; Schwaninger, Eisenberg, Schechtman, and Weiss, 2002; van Lommel, van Wees, Meyers, and Elfferich, 2001). Classically, in the early part of the experience the patient reports leaving his or her body and looking at it from a vantage point near the ceiling, looking back and down at the resuscitation process. A few studies have investigated the possibility that perceptions during the out-of-body experience (OBE) are truly veridical, by correlating the events that occurred during resuscitation when the patient was unconscious with the patient's report (Sabom 1982, 1998; van Lommel, van Wees, Meyers, and Elfferich, 2001). Criticism of this method usually centers around the observation that many patients will have knowledge of resuscitative procedures and thus be able to describe the resuscitation process in some detail (Blackmore, 1993).

There are also accounts of patients who are healed during their near-death experience (Fenwick and Fenwick, 1995; Grey, 1985; Morse and Perry, 1992; Ring and Valarino, 1998; Roud, 1990). Many of these accounts have been poorly documented and come from retrospective studies, which makes them difficult to evaluate. Prospective studies are therefore important for testing both the veridical nature of OBEs and the changes that occur during healing.

\section{Method}

The senior author (P.S.) conducted a five-year prospective study of NDEs at the Intensive Therapy Unit (ITU) at Morriston Hospital in Swansea, South Wales. She attempted to verify the out-of-body component of the NDE by placing hidden symbols on top of each patient's cardiac monitor, attached to the wall beside the bed and above head height. The symbols and pictures were mounted on brightly colored paper to attract attention, and were concealed behind ridges on the monitors to ensure that the only way of viewing them was from above. She also recorded arterial blood sample results taken during the period of unconsciousness when the NDE was assumed to have occured and any drugs administered. This was to explore the suggestions that NDEs are due to anoxia, hypoxia, hypercarbia, or drug administration. The data collection for the first year of the study included the total sample of patients who survived their admission to 
the intensive therapy unit (ITU). The data collection for the following four years concentrated on survivors of cardiac arrest and those who spontaneously reported NDEs.

\section{Results and Case Report}

The general results of this five-year prospective study of NDEs have been reported elsewhere (Sartori, 2004, 2006). We report here a detailed case report of one of the most interesting cases elicited during the study. The senior author was the patient's nurse at the time his NDE occurred, and the patient viewed her actions and those of the doctor and physiotherapist as if from an out-of-body perspective, above where his body lay in the bed. His experience also incorporated many classic elements of NDEs, including an inexplicable "healing" of a congenital abnormality. The score on the NDE Scale (Greyson 1983) was 20 out of a possible 32 . The patient gave an extremely accurate account of the events occurring during the $\mathrm{OBE}$, and the events reported happened at a time when he was deeply unconscious with his eyes closed. These events have been verified by the nurse and physiotherapist who were present, and they were also documented in the patient's medical notes by the consultant who reviewed him at the time of his experience. However, that patient did not recall viewing the hidden symbol.

\section{Case Report}

The patient was a 60-year-old Caucasian man recovering from emergency surgery for bowel cancer, following which he was very sick and developed sepsis and multi-organ failure. After five days he no longer required inotropic drugs to maintain his blood pressure, his kidneys regained normal function, and renal therapy was discontinued. Although he was still dependent on the ventilator to assist his breathing, he was making a good recovery, so it was planned that he would sit in a chair to help regain muscle tone. The nurse, physiotherapist, and sister in charge reassured the patient that it would be in his best interest to get out of bed. Within approximately five minutes of sitting in the chair, the nurse noted that the patient's respiratory rate had increased markedly and his oxygen blood saturation levels had dropped to 70 to 86 percent, from its previous 
normal level of 96 percent and above. The senior author (P.S.) then manually ventilated the patient with 100 percent oxygen provided by means of an Ambu bag, and the drop in oxygen level was rectified. Although his oxygenation remained stable above 94 percent, the patient's blood pressure then dropped to 85/50 millimeters of mercury, his skin became very clammy, and his condition deteriorated rapidly. There was a brief episode of supraventricular tachycardia that reverted spontaneously without any medication. Extra staff were called and the patient was immediately put back to bed for fear of an ensuing cardiac arrest. By the time he was put into bed he was deeply unconscious, his eyes were closed, and he was not responding to verbal command or deep painful stimuli.

A junior doctor briefly reviewed the patient and prescribed some fluid, then returned to attend another patient. The patient's condition continued to deteriorate, so the consultant anesthetist who had just arrived on the unit was called, and he performed a thorough examination of the patient. Extra fluids were prescribed and administered to improve his blood pressure. In the meantime, the junior doctor returned. The consultant inquired if the patient's pupils had been checked for response, and promptly shone a light in each eye. He remarked that they were both reacting, but that the right pupil was bigger than the left. The patient's condition stabilized and the consultant returned to his office.

During this time, the physiotherapist was concerned that she was to blame for the episode, having persuaded the patient to sit in the chair. She stood outside the bedside screens, nervously and intermittently poking her head around to check on the patient. Once he was stable, it was noticed that he had drooled from his mouth, and the nurse cleaned it, first using a long suction catheter and then a pink oral sponge soaked with water. After approximately 30 minutes, the patient began to flicker his eyelids and move his limbs, although he was still unable to respond to verbal command. He regained full consciousness approximately three hours after the event.

Once fully conscious, the medical team rounding on the ward approached his bedside and he excitedly tried to communicate something to the doctors. He was unable to speak, as he was still connected to the ventilator. The physiotherapist provided him with a letter board, on which he spelled out: "I died and I watched it all from above." This was witnessed by the doctors and nurses who were present on the ward rounds. 
The senior author then explained her research in detail to the patient and invited him to participate, and he gave written consent. Once he was no longer dependent on the ventilator and had regained his voice, the senior author interviewed him in depth. This is what the patient reported, taken from excerpts of the first interview and two follow-up interviews:

They wanted me to get out of bed, with all my tubes in me and sit in the chair. They insisted, especially one sister. I didn't want to because I felt so weak; then eventually I got out. All I can remember is looking up in the air and I was floating in a bright pink room. I couldn't see anything; I was just going up and there was no pain at all. I looked up the second time and I could see my father and my mother-in-law standing alongside a gentleman with long, black hair, which needed to be combed. I saw my father - definitely - and I saw this chap. I don't know who he was, maybe Jesus, but this chap had long, black, scruffy hair that needed combing. The only thing nice about him was his eyes were drawing you to him; the eyes were piercing; it was his eyes. When I went to look at my father, it was drawing with his eyes as well, as if I could see them both [at] the same time. And I had no pain at all. There was talking between me and my father; not words but communicating other ways - don't ask me what, but we were actually talking. I was talking to my father ... not through words through my mouth, but through my mind.

It seemed to be four to five seconds! It was unusual; I went up. ... It was so painless; there was no pain. ... I was so happy. ... I was enjoying myself. But looking back, I could see other patients as well below me. That's what I couldn't figure out: I could see everybody. I was happy, no pain at all, until I felt somebody going to my eye. I looked back and I could see my bed, my body in the bed. I could see everything that was happening on the floor. I saw doctors when I was up there; I was looking down and could see the doctors and even the sister, what she was actually doing in the ward. It was marvelous; I could see nurses around me and the doctors. I was still going up in the air and I could feel somebody going like this to my eye. [He raised his finger up to his eye.] I eventually looked back and I could see one of the doctors pulling my eye, what for I didn't know. One doctor was saying: "There's life in the eye."

I could see everybody panicking around me. The blonde lady therapist boss, she was panicking; she looked nervous because she was the one who got me out in the chair. She hid behind the curtains, but kept poking her head around to check on me. I could also see Penny, who was a nurse. She was drawing something out of my mouth, which looked to me like a long, pink lollipop, like a long, pink thing on a stick - I didn't even know what that was. I was still going up, and eventually the gentleman said to my father and my motherin-law, "He's got to go back; he's not ready yet." I was peaceful, no pain, still looking up, and I felt this ... could hear this chap telling my 
father, "Sorry, he isn't ready yet; he's got to go back." I looked up and Mam [his mother-in-law] said a few words and Dad. Eventually, I felt myself coming slowly back into my body. I went in my body on the bed and I was in terrible pain; the pain was worse then than it had ever been before. All these cables were in me, as they were before I went up. I couldn't speak because I had tubes in my throat and my nose. Then [the physiotherapist] came to speak to me and it was frustration really, because they were all asking me what happened, how I was feeling. Um ... anything wrong ... I couldn't speak; it was more frustrating when you can't speak. The physiotherapist wanted to know what happened. I couldn't speak, so she got a book with words and sayings on it. Eventually she came to a page I recognized and I pointed to that and said, "I was dead." When [the physiotherapist] asked me, I said I was dead, and I was dead, actually dead - I can tell you!

Penny: On the monitor next to your bed was something hidden on top. Could you see what it was?

No, I'll be honest with you, Pen, I didn't look. I didn't twist my head back that way; I was just looking at my side. I could see you and the doctor and two to three others around me. Pen, if that's death, it's wonderful, there's no pain at all.

Penny: Do you recall hearing anything while in this state?

Only the words that my father spoke, and the gentleman saying, "He isn't ready yet." Going back ... I heard voices down below but couldn't make out what they were saying. Only thing ... something about my eye, life there. ... I don't know what he meant by that.

Penny: I remember that. It was the consultant actually, and he looked in your eye and he shone a torch and he said, "Yes they are reacting, but unequal."

Yes, something like that, and then to my father, "He isn't ready yet; he's got to go back." Eventually ... I didn't want to go back; I was happy. But I came back into my body, and then all of a sudden it clicked that I must have been dead, something like that. And the first thing that came into my mind was [his wife]. Who was going to look after [his wife], because [his wife] depends on me?

Why I saw my mother-in-law, I haven't got a clue. I want to ask people - I seen my father and mother-in-law; why couldn't my mother have been there? Know what I mean? I didn't know my mother-in-law [she died a year before he met his wife]; I haven't met my mother-inlaw before.

Penny: How did you know that it was your mother-in-law?

Photographs. I've got photographs ... and my wife has, so I knew them all. I knew my mother-in-law died from cancer; we weren't married then.

Penny: So you had met her before then?

No. ... That's what I couldn't understand. Why was she there with my father?

Penny: So she mentioned your wife, what did she say? 
That's all, that's all.

Penny: Just said her name is it?

[The patient noncommittally said, "something like that." $\mathrm{He}$ was very nonspecific about this and he hadn't previously mentioned his mother-in-law. When asked about this, he said that he didn't know who she was at the time, but later recognized her from photos. He wasn't really concerned with her during the experience, because he didn't really know who she was.]

Penny: Did you hear any unusual sounds at all?

Not really ... only ... no. I could see a phone but I couldn't hear it; I could only see someone speaking on the phone but I couldn't hear what they were saying. I was looking down and I could see who was around me - you, Penny; two to three other doctors; sister was there; and the physiotherapist and two others.

I was enclosed in a room heading towards my father and a gentleman with scruffy, long hair that needed combing. Who the gentleman was, I haven't got a clue. I could say it was Jesus, I could say it was God, but who am I to know that? He didn't speak to me saying it was Jesus, but I know it was my father. ... My father was there.

Penny: Did he look like typical pictures you've seen of Jesus?

Sort of, yes, but in the pictures Jesus is in white, like a white cloak, whereas it could have been a white shirt, mostly white. My father was in his working clothes ... in what he used to wear to work, always smart; he was always a very smart gentleman. Collar and tie, these were his working gear. I don't know why I pictured him that way. Jesus was wearing a shirt. He wasn't standing on two legs, only from the waist up I could see. Like you see on TV, cut off half way.

Penny: Was that the same for your dad, was he cut off half way?

Yes, yes, they were both like that. They weren't standing up and walking towards me; I was going towards them.

Penny: Would you say that you were up at the height of the ceiling when you were out of your body?

There was no ceiling.

Penny: You could have been higher than the ceiling?

$\mathrm{Oh}$, yes, there was no ceiling at all. That's what I mean, it was just a room ... what I thought was a room. It could have been a square tunnel going up towards my father, but no barrier stopping me going up, no ceiling; it was a complete clear entrance.

Penny: So when you were looking down at your body, how high up in the air do you think you were?

Oh, God, it's hard for me to say. ... Um ... well, I'm a carpenter so I've been up on roofs. Say a three-story, two-story building. About that, looking down. A big house height - I could see my body and I could see what was going on. I wasn't so high up that they were like ants. I worked on the Guild Hall clock; I was up there and the people 
were ants. No, not as high as that; say, a three-story building or a twostory building.

Penny: In this out-of-body state, did you try to communicate with any of the nurses around you?

The only thing I know is the doctor said, "There's life in the eye." I looked up and I was happy and the gentleman was telling my father, "He's not ready yet; he's got to go back." I don't know what was happening, but I gradually came back down into my body and that's when the pain started happening again.

Penny: When you came back did your father just fade in the distance, and this man?

Yeah, when I came back into my body. I must have been seeing my father when I came back into my body, then said goodbye or something like that, and it eventually cleared, but I remember I was in terrible pain again. You were there, Penny, and two doctors. But you with the lollipop, sponge, yes, like a mouth wash.

Penny: I can remember doing that, but at the time you were completely unconscious and your eyes were closed.

Well, I could see that, as plain as I can see you now [adamant].

Penny: Did you hear me say that I was going to clean your mouth?

No, I didn't hear anything. I was just looking back and could see you doing something with my mouth and seeing this long, pink thing.

Penny: Was there any part of this experience that frightened you?

No, not at all. In fact it was beautiful; it was wonderful.

Penny: Is the experience still very clear in your mind?

$\mathrm{Oh}$, yes, yes. It's as if it happened yesterday; I'll never forget it. Not like the hallucinations.

Penny: What do you remember about the hallucinations?

Oh, they used to happen every time I pressed my morphine button, you know, the PAC or PCA [patient-controlled analgesia].

Penny: Yes, the PCA.

[The morphine PCA had been discontinued a few days prior to his NDE, and no such drugs were administered on the day of his NDE.]

Every time I pressed that button, the hallucinations would start. The room would spin around, the walls would move, and I'd see stupid things that weren't there.

Penny: How did you know they were hallucinations?

I knew they weren't real; they were a bit like, like, dreamlike, but worse.

Penny: Were they similar to the other experience you remembered?

$\mathrm{Oh}$, no. They were very different. That near-death experience was real; there's no doubt in my mind. The hallucinations, well, they weren't real; it was like a bad dream gone wrong. Stupid things were happening, you know? No, they were both very different experiences.

Penny: Do you feel like you've learned anything from the experience?

Well ... no fear about death. 
[Another remarkable aspect of this NDE was the fact that the patient was later able to open his previously contracted hand. This was established during follow-up when he misunderstood one of the questions. When born, the patient had cerebral palsy, which resulted in a contracture of his right hand. He had previously worn a splint on his hand and had never been able to open it.]

Penny: When you were in this state and not in your body, were there things you could do that you can't in your physical body?

Well, yeah, that's what I mean; when I came back down I could open my hand. [He misinterpreted the question.] This hand has always been strong [left] but this hand [right] used to be like this [fist clenched and contracted under]. All my life, for 60 years, my arm has always been like this; I could never open it. My father used to say, "The monkey is in the cage." Now I can open it. They told me that my kidneys weren't working properly, and now they're working perfect, so I don't know what that was. Also, I know I lost a lot of weight. My ankles used to get very swollen and now they're like a two-yearold's; they're thin. Even my sister was surprised about my hand. I've got cerebral palsy and my hand used to be like this [clenched and twisted underneath]; now I can open it. It feels a bit tight, but I do open it.

Penny: Have you ever been able to open it like that before?

No, I've never been able to open it like that, Penny. Never; only a little bit.

Penny: That is only since the experience? Or was it before?

Since the experience. I can do everything with it, all the cooking. They told my sister that I didn't have to have the kidney treatment because it was all working ... and my hand was unusual. Also, what I noticed since I came home, I used to turn my foot in; I can't understand this, but I don't do that anymore. I'm walking straight as a die, don't know why; I've got taller - not taller, but I walk straighter. Also, they cured my hand and kidney but gave me drop foot, but now my drop foot has gone. I don't know why ... they say it don't go; it's bound to go in some cases.

\section{Discussion}

Was the patient's experience just a mental model constructed from his residual sight, sound, and touch? This patient had been in the ITU for eight days prior to the experience and was very familiar with the layout of the unit and the daily routine. At this point, it is pertinent to examine the features of his OBE separately. 


\section{Veridical Features of His $O B E$}

1. The doctor shining the light in his eyes. The doctor who checked his pupils was the consultant anesthetist, who entered the ITU for the first time that day, just as the patient's condition deteriorated. The junior doctors were unavailable; subsequently the consultant reviewed the patient. When the patient's condition stabilized following the administration of fluid to increase the blood pressure, the junior doctors arrived and the consultant returned to his office until he began the ward rounds later that afternoon. The consultant checked that the patient's pupils were reacting by shining a light into them. $\mathrm{He}$ remarked, "Yes, they're reacting, but unequal." The patient reported hearing the doctor saying, "There's life in the eye" or "something like that." This was inaccurate, although this highlighted his interpretation of what was said and was a good comprehension of what the consultant meant.

The patient was unconscious by the time the consultant reviewed him, and remained unconscious when the consultant left the bedside. It was only as the ward rounds approached the patient's bed area four hours later that he regained full consciousness and excitedly tried to communicate what he had experienced. The patient correctly identified the consultant as having shone the light in his eyes, rather than one of the junior doctors with whom he was familiar. The patient was deeply unconscious at this time and had not previously seen the consultant that morning, although he had seen the other junior doctors. However, it is possible that he heard the consultant's voice at the time of unconsciousness, which may have contributed to the construction of a mental model.

2. The nurse cleaning his mouth. When the patient had been put back to bed, he had drooled from the side of his mouth. Once his condition had stabilized, the nurse cleaned his mouth. He knew who his nurse for the day was, and was familiar with the nursing procedures to be performed. He knew that his mouth was cleaned by using a pink sponge dipped in water. When performing any nursing procedures the nurse always explains her actions, even if the patient is unconscious. He could therefore have heard the nurse explain her actions, although he adamantly denied having done so, and could also have felt her cleaning his mouth. However, because he had drooled, a long suction catheter, normally used for endotracheal suction, was used to clean the oropharyngeal secretions from the back of his throat. 
This long catheter was used in preference to the shorter, hard, plastic Yankauer sucker, as it is softer and more comfortable for the patient; this is not the usual procedure, as most nurses use the Yankauer sucker. After his mouth was cleaned, a moist pink sponge was put into his mouth to freshen it up. The pink sponge is not long, as the patient reported, but the suction catheter that was used first was long. He could therefore have "seen" both pieces of equipment. Also, the secretions cleaned away were pink in color.

3. The physiotherapist "poking her head around the curtains." The patient also reported seeing the physiotherapist looking very nervous and "poking her head around the curtains" to see if his condition was improving. The same physiotherapist was on the ward rounds at the time he reported the experience. She had been on duty all day, and the patient was aware of this fact. It is possible, but not confirmed, that she inquired verbally about the patient's condition, as she was "poking her head around the curtains." Thus the patient could have heard her asking, which could have contributed to the construction of a mental model. The patient's eyes were closed throughout the period the physiotherapist was checking on his condition. However, if his OBE was a mental reconstruction, it is surprising that the patient should report her to be "poking her head around the curtains, looking very nervous." It would be more likely that he would construct a view of her standing closer to the bedside, without the need to "poke her head around the curtains."

\section{Was His OBE a Mental Reconstruction?}

Could a mental model have been constructed during the four hours it took for the patient to regain full consciousness? Could it have been his brain's attempt to make sense of what had occurred through the senses, especially residual sight, sound, and tactile stimulation? The discrepancy between what the consultant said ('Yes, they're reacting, but unequal") and what the patient reported he said ("There's life in the eye") could be accounted for by the possibility that he was confused, and so unable to pay full attention to verbal cues. This would suggest that "viewing" the situation with such clarity would not be possible if it was due only to a mental model reconstructed from what he could hear and feel. If the mental reconstruction was based on what he could hear, then it would be expected that he would accurately report the verbal cues he had heard. 
Despite these discrepancies, the patient's description of what happened while he was unconscious was extremely accurate and was reported immediately as soon as the patient regained full consciousness. It is possible that some of the information could have been gained from the senses, but that is an incomplete explanation for the detailed events described by the patient and witnessed by the senior author. The experience remained vivid and accurate when recalled on follow-up on several occasions from one year to five years after the experience.

\section{Did the NDE Happen as the Patient was Regaining Consciousness?}

While it is impossible to speculate on the timing of the patient's experience of "meeting" his deceased father and mother-in-law, it is possible to say that the experience of observing the nurse cleaning his mouth with what looked like a pink lollipop, and observing the doctor shining a light into his eyes, must have happened at least three hours before the patient regained full consciousness. As the medical records show, the patient was deeply unconscious with his eyes closed at the time when those events occurred, and the experience of undergoing those events must have been contemporaneous with their occurrence rather than happening four hours later while the patient was regaining consciousness.

\section{Was the NDE Attributable to Abnormal Arterial Blood Gases?}

Prior to loss of consciousness, the patient's blood saturation level of oxygen decreased from 96 percent to between 70 and 86 percent. This decrease was promptly rectified by manually ventilating with 100 percent oxygen. The oxygen levels briefly decreased again but then increased again and remained at 94 percent and above. He was still conscious when the oxygen levels were normalized. An arterial blood gas sample was not extracted until approximately an hour after the event, by which time the patient's condition was stable. The results were as follows: the partial pressure of oxygen $\left(\mathrm{pO}_{2}\right)$ was 10.2 kilopascals $(\mathrm{kPa})$, within the normal range of 10 to $13 \mathrm{kPa}$; the partial pressure of carbon dioxide $\left(\mathrm{pCO}_{2}\right)$ was $10.6 \mathrm{kPa}$, above the normal 
range of 4 to $6 \mathrm{kPa}$; and the acidity $(\mathrm{pH})$ was 7.176 , more acidic than the normal range of 7.35 to 7.45 .

Although the oxygen level was normal, the carbon dioxide was elevated. Effects of high levels of carbon dioxide (hypercarbia) may include some features similar to components of NDEs, include feelings of ineffability, a sense of bodily detachment, telepathic communication with a religious figure, perception of a bright light, memories from the past, and feelings of cosmic importance. Other effects of hypercarbia include seeing animated objects, compulsion to solve mathematical problems, the perception of geometric figures or patterns such as stained glass, and frightening perceptions of "shapeless and objectless horror." Some even described the feeling of hypercarbia as a "real dream" (Meduna, 1950).

This patient did not report any dreamlike qualities, nor did he report any geometric patterns or frightening aspects, nor the compulsion to solve mathematical problems. His OBE was not merely a sense of bodily detachment, as may be reported in hypercarbia, but a definite feeling of existing independently of his body and accurately viewing events that were later verified by the staff present. Many who undergo an NDE are adamant that the experience was not a dream. In addition, two other patients in this study who reported a NDE or an OBE had levels of carbon dioxide that were within the normal range at the time of their experiences.

It should also be emphasised that this patient's blood tests can act only as a guide, as it is unknown if the NDE was occurring at the time the blood was extracted. In fact, the blood was extracted approximately an hour after the events viewed by the patient from an out-ofbody perspective, which may indicate that the levels had increased gradually over the hour and did not accurately reflect the level at the time of the OBE. The time that elapsed from when the patient was conscious in the chair to when he was put back to bed and viewed events from an out-of-body perspective was approximately 10 to 15 minutes. It is unlikely that the levels of carbon dioxide would have risen to the high level in such a short period of time.

\section{Was the Experience Attributable to Drugs Administered?}

During the experience there were no intravenous drug infusions in progress and no drugs were administered. He was given only fluid to improve his blood pressure. 
Did the Patient Construct the NDE to Help the Nurse Who Was Looking After Him?

Before the patient's experience, the nurse's research into NDEs had been concerned only with patients who had survived cardiac arrest. The research had not previously been discussed with the patient, and he had no knowledge that such research was being conducted. In fact, had the patient not reported his NDE, he would not have been asked about what he recalled during the time he was unconscious, and would not have been included in the research.

The fact that he reported the experience immediately upon regaining consciousness makes it highly unlikely that he had made it up. Following a period of unconsciousness, patients are usually quite dazed, and constructing an elaborate scenario to please the nurse would be most difficult. Furthermore, the nurse was not present at the time that he regained full consciousness and reported the experience to the doctors on the ward rounds.

\section{The Unusual "Healing" of His Contracted Hand}

It was documented in the patient's medical admission notes that he had cerebral palsy with a right spastic hemiparesis. The patient stated that his hand was claw-like and had been so all his life; this was supported by the testimony of his sister. The extent of the contracture had not been formally assessed or documented prior to the NDE. However, a splint had been made for the patient's hand by the hospital appliances department several years prior to the current hospital admission. The patient stated that the splint had not been effective and that his hand remained contracted. The medical and physiotherapy notes were checked to see if extensive physiotherapy had been performed on his hand; it had not. However, it was documented in the physiotherapy notes that there was increased muscle tone in his contracted hand prior to discharge. This was discussed with the physiotherapist, who explained that the hand should not be able to open without an operation to release the tendons that had been in a contracted position for 60 years. No such operation had been performed. It remains unexplained how it is possible for the patient to be able now to open and use his previously contracted hand.

There is no reason to disbelieve the patient's or his sister's statement regarding the extent of his contracture prior to his NDE. Indeed, the fact that his contracture had resolved was mentioned only 
when the patient misinterpreted one of the questions asked during the in-depth interview. Had he not misinterpreted the question, the fact that he is now able to open his hand may have gone unnoticed.

\section{Conclusion}

There are many aspects of this case for which our current brain/ mind models cannot provide an adequate explanation. Despite not identifying the hidden symbol, the patient accurately reported the actions of the medical personnel present during a time when he was deeply unconscious with his eyes closed. The fact that he was able to open his previously contracted hand defies explanation. The veridical details of this case are corroborated by the medical notes and the testimonies of the patient, his nurse, and physiotherapist, who were present at the time the experience occurred. This study confirms that cases of interest that cannot be dismissed or ignored can be captured during a prospective study.

This interesting case history was elicited from one small prospective study, conducted in one hospital. Further prospective research on a much larger scale is warranted in order to provide a wider understanding of the NDE and, indeed, consciousness. Although this is only one case, it strengthens the cumulative experience derived from many other individual cases (Sabom, 1998, Cook, Greyson, and Stevenson, 1998; Sabom, 1998; van Lommel, van Wees, Meyers, and Elfferich, 2001) that suggest that our current models of consciousness must expand in order to provide an adequate explanation of NDEs.

\section{References}

Blackmore, S. J. (1993). Dying to live: Near-death experiences. Buffalo, NY: Prometheus.

Cook, E. W., Greyson, B., and Stevenson, I. (1998). Do any near-death experiences provide evidence for the survival of human personality after death? Relevant features and illustrative case reports. Journal of Scientific Exploration, 12, 377-406.

Fenwick, P., and Fenwick, E. (1995). The truth in the light: An investigation of over 300 near-death experiences. London, England: Headline.

Grey, M. (1985). Return from death: An exploration of the near-death experience. London, England: Arkana.

Greyson, B. (1983). The Near-Death Experience Scale: Construction, reliability and validity. Journal of Nervous and Mental Disease, 171, 369-375.

Greyson, B. (2003). Incidence and correlates of near-death experiences in a cardiac care unit. General Hospital Psychiatry, 25, 269-276. 
Lawrence, M. (1995). The unconscious experience. American Journal of Critical Care, 4, 227-232.

Lawrence, M. (1997). In a world of their own: Experiencing unconsciousness. Westport, CT: Praeger.

Meduna, L. J. (1950). Carbon dioxide therapy. Springfield, IL: Charles C Thomas.

Morse, M., and Perry, P. (1992). Transformed by the light: The powerful effect of neardeath experiences on people's lives. New York, NY: Villard.

Ring, K., and Valarino, E. (1998). Lessons from the light: What we can learn from the near-death experience. New York, NY: Plenum/Insight.

Roud, P. C. (1990). Making miracles. New York, NY: Warner Books.

Sabom, M. (1982). Recollections of death: A medical investigation. New York, NY: Harper and Row.

Sabom, M. (1998). Light and death: One doctor's fascinating account of near-death experiences. Grand Rapids, MI: Zondervan.

Sartori, P. (2004). A prospective study of NDEs in an intensive therapy unit. Christian Parapsychologist, 16, 34-40.

Sartori, P. (2006, Spring). A long-term prospective study to investigate the incidence and phenomenology of near-death experiences in a Welsh intensive therapy unit. Network Review, No. 90, pp. 23-25.

Schwaninger, J., Eisenberg, P. R., Schechtman, K. B., and Weiss, A. N. (2002). A prospective analysis of near-death experiences in cardiac arrest patients. Journal of Near-Death Studies, 20, 215-232.

van Lommel, P., van Wees, R., Meyers, V., and Elfferich, I. (2001). Near-death experience in survivors of cardiac arrest: $A$ prospective study in the Netherlands. Lancet, 358, 2039-2045. 